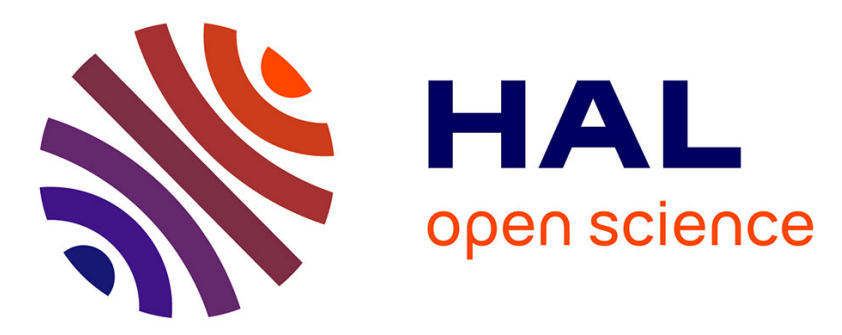

\title{
Interaction Analysis in Performing Arts: A Case Study in Multimodal Choreography
}

\author{
Maria Christou, Annie Luciani
}

\section{To cite this version:}

Maria Christou, Annie Luciani. Interaction Analysis in Performing Arts: A Case Study in Multimodal Choreography. First International Conference on Arts and Technology, Sep 2009, Yi-Lan, Taiwan. pp.97-104. hal-00910684

\section{HAL Id: hal-00910684 \\ https://hal.science/hal-00910684}

Submitted on 3 Jul 2014

HAL is a multi-disciplinary open access archive for the deposit and dissemination of scientific research documents, whether they are published or not. The documents may come from teaching and research institutions in France or abroad, or from public or private research centers.
L'archive ouverte pluridisciplinaire HAL, est destinée au dépôt et à la diffusion de documents scientifiques de niveau recherche, publiés ou non, émanant des établissements d'enseignement et de recherche français ou étrangers, des laboratoires publics ou privés. 


\title{
Interaction Analysis in Performing Arts: A Case Study in Multimodal Choreography
}

\author{
Maria Christou and Annie Luciani \\ Laboratoire ICA-ACROE \\ www-acroe.imag.fr \\ Grenoble INP \\ 46 av. Félix Viallet, 38000 Grenoble, France \\ \{maria.christou, annie. luciani\} @imag.fr
}

\begin{abstract}
The growing overture towards interacting virtual words and the variety of uses, have brought great changes in the performing arts, that worth a profound analysis in order to understand the emerging issues. We examine the performance conception for its embodiment capacity with a methodology based on interaction analysis. Finally, we propose a new situation of multimodal choreography that respects the aforementioned analysis, and we evaluate the results on a simulation exercise.
\end{abstract}

Keywords: Embodiment, Digitally enhanced performance, Interaction methodology, Dance.

\section{Introduction}

Even though technologies have since very early on been correlated to performing arts, it is the in the digital era that great changes were introduced in the way we treat and perceive the body, space, time and the interactivity of a performance [1]. Contemporary artistic creations use more and more frequently information and communication technology as composite of an art installation or spectacle, and sometimes even for appointing virtual interactive worlds. Under this context, the interactive environment - the interface of interaction - in an art performance becomes a powerful dramaturgic element. This ever-growing use of modern technology in art creation and variety of different uses, make a great field for analysis research from which interesting results can be subtracted concerning interactivity.

To examine the properties and the relations between the participants of an interactive performance, we propose a complete methodology based on interactive theories that promote embodiment.

The proposed methodology is applied to a case study of a Dancer - Public Environment interaction. Embodiment is inherent to dance for a dancer; it is also this notion that makes the choreographer and the public able to understand the 
communicated feelings through the motion and the interaction. It is then important to design the interaction having interactive scenarios in mind.

In the triangle of participating actors of a dance performance, dancerchoreographer-public all have different ways of seeing and perceiving the motion in the digital environment. Most computer programs produce movements based on descriptive models and not generating ones. However, choreographer needs to express the movement in terms of a cause and not by describing the result [2]. Thus, it is important to adopt dynamic models to generate movements. We argue that a physically based particle system, such as MIMESIS [3], can make the procedure of designing a digital performance, and also the simulation results, to be more plausible to the dancer and more intuitive as a concept of both dancer and choreographer.

Our study case has been developed and evaluated during our collaboration with the choreographer Wolf $\mathrm{Ka}$, creator of an interactive piece designed for dancer and spectator [4].

\section{The Typology of Actors and of their Interactions}

The procedure for defining the interaction system in a spectacle installation is to find the basic roles and assign them properties, then to put them in relation and examine their interactions. Although the beginning of this deliberation was an installation for a dancer and a spectator, it is essential to place this problem within a larger framework in order to better understand the nature of interaction and to continue seeking possibilities that are not yet employed.

After having tested different cases for modelling the roles in an interactive dance performance, we came to the conclusion of five types of factors.

The first factor is the dancer or dancers. It is important to note that the properties of the dancer's role are different if there are several dancers on the scene; so we define two sub-types correspondingly.

A second factor will be what is called the "virtual body". The virtual body is the representation of the dancer in the virtual world. Motion sensors can be used to capture the dancer's movement. We also have two subcategories here, depending on if the sensors appertain to different persons or to the same one.

In terms of the virtual world we come to the third factor which is the animation environment, that is to say the virtual space of the interaction. We can distinguish two cases of this environment, either it is a fixed milieu or it allows movement.

The public in an interactive performance has an active role too. As the dancer, the audience too has a virtual equal. Its representation in the virtual space can be made by one or multiple points. Again we set two subtypes, according to the dependence of the points, whether they belong to the same person of the public or to different ones.

Finally the last factor is the public, members of the audience, who are able to use the digital interaction system.

We can see below a diagram overview of the factors we are going to use in this paper. 


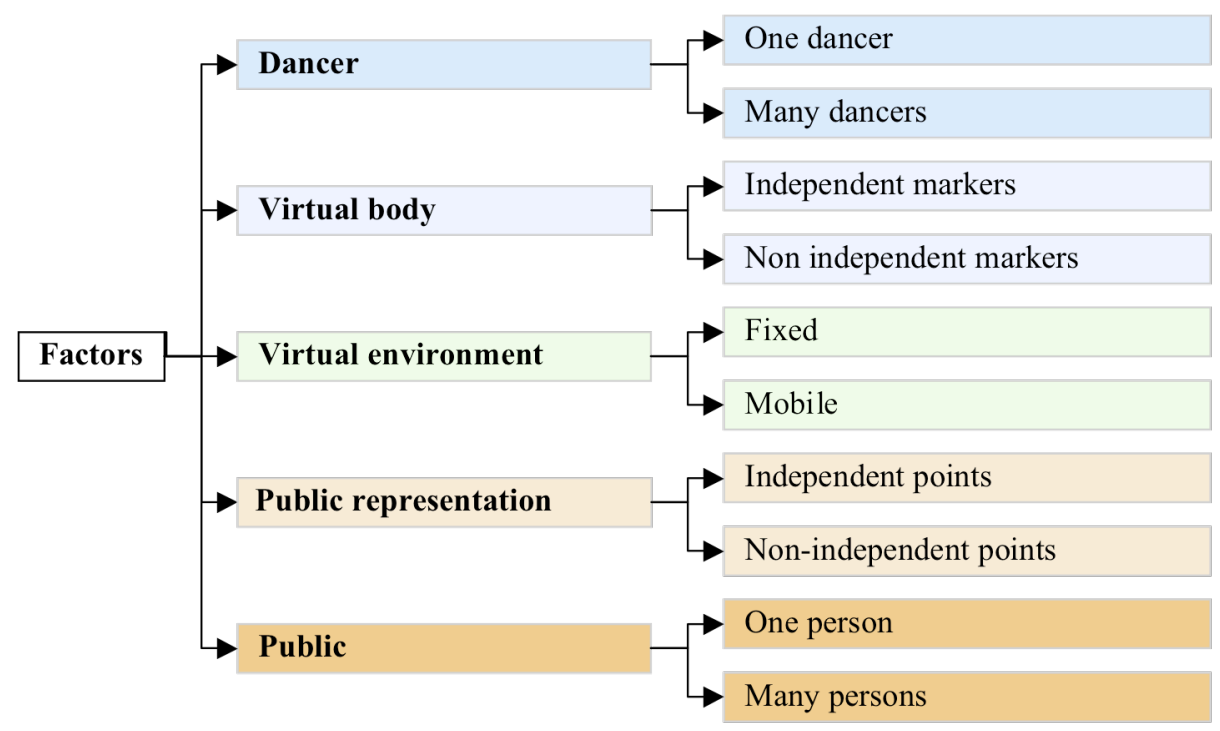

Fig. 1. The typology of the interacting factors

\section{The Interactive Analysis}

We examine all the possible types of interaction between the different factors in order to verify how the adopted representations could be suitable in supporting the embodiment criteria of the perceptibility of the artistic intention. We try to explore how to enforce the sensation of "being with" at the time of the realisation and the memorability of the performance, even before considering aesthetic appraisal. We examine through this prism some preliminary cases of the dance performance "Moving by Numbers" by Wolf Ka.

The analysis process has two stages - firstly, it is necessary to define the behavioural possibilities of the factors. Secondly, we define the type of interaction between them. The combination of these two can give great graphic variations. We can summarise this result into a metaphor in order to render the interaction more familiar to the human experience.

Our analysis showed that there were some challenging points in the conception of the interactions in a preliminary version of "Moving by Numbers". The first point that challenges the comprehension for the dancer is the integration of multiple spatial scales. In fact, the dancer can move freely into space whereas the virtual environment on which he/she acts remains fix. This leads to ruptures of the relation between the dancer and the virtual environment. The second point is the change of the virtual environment by the spectator. Indeed these kind of changes break the movements effected and perceived under the natural assumption of the context permanence, if we don't give any prior indication that allows us to anticipated them. 


\section{A New Situation}

While getting in more depth of these study cases, we felt the need to explore the interaction levels for manipulating the models of the virtual world. Claude Cadoz has summarised the essential levels of gestural control [5] to the following three, which we explain for our case:

- Instrumental level: where the relation between the human and the model is direct and results in the excitation of the structure (triggering the movement).

- Parametric level: where the gesture does not result in an animation but it modifies the properties of the model. This modification aims at modulating the type of movement (i.e. how the model behaves).

- Structural level: where the gesture changes completely the structure of the model.

We argue throughout our experimental experience in the context of the Enaction Research, that the intervention to the Instrumental Level is the easiest to perceive and to embody. Changes on parametric and structural level, during the performance and without full attention can be harder to understand.

Under the light of these observations, we have proposed a new artistic situation. We suggest another kind of interaction between the user and the environment. In our case, the spectator does not alter the parameters or the structure; he is rather an equal co-player on this Instrumental Level. In this new situation, all the factors will be integrated in the same installation in an interaction with an artistic value.

The interaction between the dancer and the spectator, who now becomes a user, is made through and with the virtual environment model. It is a case of a triptych conception of dancer-environment-user where the interactivity respects the instrumental metaphor.

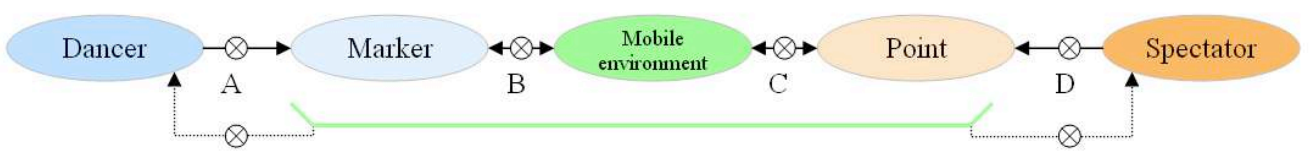

Fig. 2. The interaction scheme for the new situation

Our interaction system involves all the factors seen in the typology. More precisely we have:

1. A dancer equipped with a motion capture point,

2. his virtual body which in this case is represented by a mass that is interaction with

3. the environment which is a formation of masses in a flock of birds or a fish school, and with which also interacts

4. the representation of the user in the virtual space by a point 
5. and the user itself who moves his pointer in the environment trough a manipulator.

We could employ a metaphor for this system, where the dancer guides the flight of birds and the spectator comes to disturb this flock. The virtual environment is constituted of a physical model of a flock and the interactions between it and the other actors: the dancer's and user's virtual representations.

\section{The Modelling of the Virtual Elements and their Interactions}

Methodology and modelling should not be regarded as two independent fields of development. The physical modeling approach suggests exactly the opposite. For the modeling work we have used the software MIMESIS whose approach to motion simulation it is based to Newtonian physics principle of Action-Interaction.

The interaction system we suggest has three virtual agents: the dancer's and the user's virtual representations, and the flock formation. The three are present in our virtual environment and in our model.

We chose to simulate the relation between the masses of the flock in a way to approach the behaviour of boids [6] for representing birds' formations. The inertial masses of the flock are connected in cohesion forces on agglomeration (Fig. 4, left). The cohesion function that we used is like the Van der Waals intermolecular cohesion forces. It is composed of three zones according to the distances between the interacting bodies. For long distances, it makes the birds fly free. For medium distances the interacting bodies are attracted, as for very short distances a repulsive force tends to separate them. Then at the medium and short distances, the combination between attractive and repulsive forces creates a cohesion zone keeping the birds together to form an ensemble.
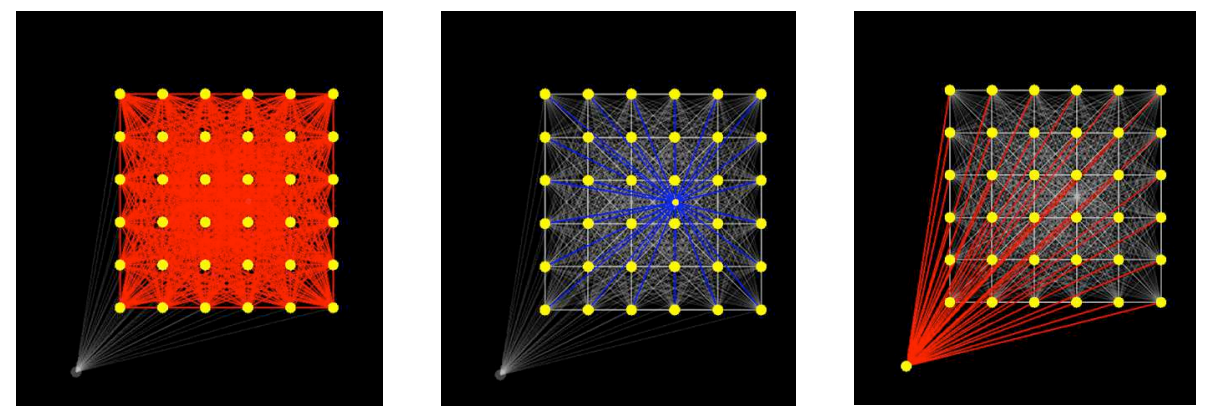

Fig. 3 The physical model and the interactions as seen in MIMESIS for: The Flock (on the left) here highlighted the cohesion interactions between the agglomerate masses - The Dancer (on the middle) spring-type interaction between the dancer and the agglomerate - The Spectator (on the right) repulsion interaction between the spectator and the agglomerate. 
Then each of these masses of the flock of birds is connected to two other masses that represent respectively the dancer and the user. With the virtual dancer there is an damping spring relation (Fig. 4, in the middle). It makes the "birds" flying around it. And with the virtual spectator, the force is repulsive, making it to repel the flock, like a predator (Fig. 4 , on the right).

\section{The Simulation Exercise}

Our proposed model needs two simultaneous and real-time inputs, one from the dancer and one from the spectator who is a member of the audience. For the audience input we suggest a joystick (or mouse) input. The dancer's motion capture introduced aspects we took into account. We decided not to change the scale factor for the dancer, so the correspondence between his movements and the animated ensemble would be in the closest association possible. Concerning the motion sensor and taking into consideration the type of the movement we imagine to acquire, we concluded to place one sensor on the head of the dancer. The artistic approach proposed does not consist a final suggestion for performance. It is a scenic proposition answering to our interaction design demands and using the initial concept of interaction proposed by Wolf Ka.

For the new situation, we transferred the CORDIS-ANIMA algorithms [7] used in the MIMESIS software to a platform able to host the motion capture and to treat the computation demands of the simulation and projection. There, we implemented six examples with different parameter settings, and two different visualisations. A very important part in this methodology is assigned to parametrizing the model. Proper parameters are able to promote the embodiment. This game of parameters, the phenomenology, plays a great role in the final experience as we remarked during the response of the dancer to different settings.

Table 1. Parameters of the relations between the masses of the model as used in MIMESIS.

\begin{tabular}{|c|c|c|c|c|c|c|}
\hline \multicolumn{2}{|c|}{$\begin{array}{l}\text { Agglomerate } \\
\text { (3-level cohesion) }\end{array}$} & \multicolumn{2}{|c|}{$\begin{array}{l}\text { Dancer } \\
\text { (Damped spring) }\end{array}$} & \multicolumn{3}{|c|}{$\begin{array}{l}\text { Spectator } \\
\text { (Repulsion) }\end{array}$} \\
\hline $\begin{array}{l}\text { 1rst level } \\
\text { elasticity }\end{array}$ & $1,00 \mathrm{e}-05$ & Elasticity & $1,00 \mathrm{e}-06$ & $\begin{array}{l}\text { 1rst } \\
\text { elasticity }\end{array}$ & level & 0,001 \\
\hline $\begin{array}{l}\text { 1rst level } \\
\text { viscosity }\end{array}$ & $1,00 \mathrm{e}-04$ & Viscosity & $1,00 \mathrm{e}-04$ & $\begin{array}{l}\text { 1rst } \\
\text { viscosity }\end{array}$ & level & $1,00 \mathrm{e}-05$ \\
\hline $\begin{array}{l}\text { 1rst level } \\
\text { threshold }\end{array}$ & 1 & Threshold & 2,5 & $\begin{array}{l}\text { 1rst } \\
\text { threshold }\end{array}$ & level & 2,5 \\
\hline $\begin{array}{l}\text { 2nd level } \\
\text { elasticity }\end{array}$ & $1,00 \mathrm{e}-10$ & & & $\begin{array}{l}\text { 2nd } \\
\text { elasticity }\end{array}$ & & $1,00 \mathrm{e}-06$ \\
\hline $\begin{array}{l}\text { 2nd level } \\
\text { viscosity }\end{array}$ & $1,00 \mathrm{e}-06$ & & & $\begin{array}{l}\text { 2nd } \\
\text { viscosity }\end{array}$ & & $1,00 \mathrm{e}-05$ \\
\hline $\begin{array}{l}\text { 2nd level } \\
\text { threshold }\end{array}$ & 1,2 & & & $\begin{array}{l}\text { 2nd } \\
\text { threshold }\end{array}$ & level & 6 \\
\hline
\end{tabular}

In the simulation exercise that we have conducted with the dancer who was implied at the work of origin, we tested the different settings (variations to the 
elasticity, viscosity and distance level of the interactions), the different visualizations (coatings), and we examined the users' response.
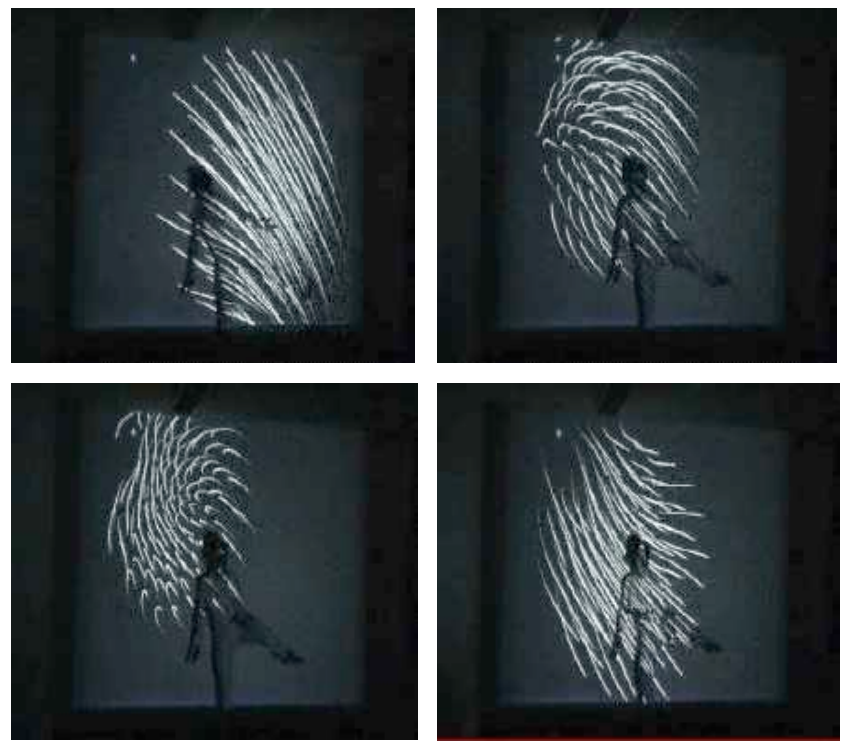

Fig. 4. Snapshots of the Flock simulation exercise. The flock of birds exhibits a cohesive behavior and it follows the motion of the dancer.

We noticed that the dancer integrated with great facility the interaction with the virtual world, the immersion was intuitive and we didn't need to give any instructions. There was a high degree of engagement from the part of the dancer and the spectator, and the given animations and dancing movements were of great interest. It was also interesting to see how the different coatings, one where the masses were spheres and a second where they had trails, changed the dancing behavior. In the first case the dancer tried to round up the flock around her, and in the second she was dancing so to promote movements of the flock that crossed her body.

\section{Conclusion and Perspectives}

There is a question that is always present when designing an interface for a computer-mediated interaction: how do we offer to users a meaningful experience and create a believable virtual word? The method that we developed and followed for this case-study is based on the Embodiment theory, which tries to describe possible methods and practices to overcome such questions.

The proposed simulation exercise does not mean to be an integral spectacle; it is suggested as an example for implementing all parts of the produced theory and methodology. It can be though easily modified to employ new ideas, as it is very flexible. 
The physical models are also by nature very modular and flexible to modifications. All the physical models are combinable and compatible. That allows us to integrate a lot of models within the same scenography.

Finally this work proposes well-founded and specific schemes of interaction for choreographers interested in designing an interactive performance, and it might give them the need to explore the interactions with physical models.

As a theoretical perspective, the underlying fascinating question of embodiment in a complex interactive environment may have here an experimental support. One fruitful track of research is, in our opinion, the analysis of what we called "the interaction metaphors" considering the whole system.

A very interesting subject of research that sprung from this work, is the question of the duality of the body (physical - virtual) and with that the possibility to play with the frontier of what it is interior and what exterior. The passage from "object of the environment" to "object near the hand" to "object in hand" is a transforming process for both the instrument and the man [8]. Man transforms the object to instrument; instrument transforms the man into an instrumentalist. This last phase of incorporating the object is exactly the beginning of the embodiment process. Embodiment as well as disembodiment (the inverse process) are basic processes of artistic creation and constitute a rich field of research by virtue of interactive technologies.

\section{References}

[1] Steve Dixon: Digital Performance: A History of New Media in Theatre, Dance, Performance Art, and Installation. Cambridge, MA and London. The MIT Press (2007)

[2] C. Hsieh, A. Luciani : Generating dance verbs and assisting computer choreography. In Proceedings of the 13th Annual ACM international Conference on Multimedia (2005)

[3] Matthieu Evrard, Annie Luciani, Nicolas Castagné : MIMESIS: Interactive Interface for Mass-Interaction Modeling, In Proceedings of CASA 2006 (2006)

[4] Wolf Ka : Man in |e|space.mov / Motion Analysis in 3D Space, In ACMM'05, Singapore (2005)

[5] Claude Cadoz: Gesture and Music in Trends in Gestural Control of Music. IRCAM Editions (2000)

[6] C. W. Reynolds : Flocks, Herds, and Schools: A Distributed Behavioral Model, in Computer Graphics. In SIGGRAPH '87 Conference Proceedings (1987)

[7] Cadoz, C., A. Luciani and J.-L. Florens: CORDIS-ANIMA : a Modeling and Simulation System for Sound and Image Synthesis - The General Formalism (1993)

[8] Annie Luciani, Charlotte Magnusson, Nicolas Castagné: Final report on technological specifications for Enactive Interfaces. In Deliverable D.IA2.6. 3 November 2006. NOE Enactive Interfaces (2006) 